\title{
The Effect of Bankruptcy Laws on the Valuation of Risky Consumer Debt
}

\author{
Stanley J. Kon* and John G. Thatcher**
}

\begin{abstract}
In a market setting with perfect information, a consumer recognizes that he can influence the state-contingent returns, and hence the price, of his risky debt by the decision variables that determine the collateral and promised payments. This paper examines the effect of bankruptcy laws on the feasible consumption opportunities of borrowers and lenders in order to determine the necessary requirements for the bilateral debt market to be perfectly competitive.
\end{abstract}

\section{Introduction}

This paper is concerned with the properties of a decentralized general economic equilibrium with financial markets that consist of shareholder interest in firms and bilateral debt contracts. The characteristics of a stock market economy when consumer default is ruled out by restrictions on consumer behavior are discussed in Diamond [5], Dreze [6], Gevers [8], Hart [13], and Grossman and Hart [11]. Markets for firms' shares are assumed to exist as an imperfect substitute for the complete contingent commodity markets in the Arrow [1] and Debreu [4] models. However, the problem of consumer default in a general equilibrium framework has been pursued exclusively in the context of a central clearing market. Stigum [17, 18] and Arrow and Hahn [2] introduced the current settlement aspects of default, Grandmont [9] considered the impact of the anticipation of future default, and Green [10] has dealt with both aspects simultaneously. In a central clearing market, consumers lack full informa-

\footnotetext{
*University of Michigan, Ann Arbor, MI 48109-1234.

**Marquette University, Milwaukee, WI 53233. This paper was submitted in honor of A. James Boness. The authors are grateful for the helpful comments from an anonymous referee. This research was partially supported by a summer grant from the University of Michigan Graduate School of Business Administration.
} 
tion concerning the identity of the issuer of contracts they buy. In contrast, a bilateral debt market depicts contracts as being created through a process of negotiation between a set of consumers. Consumers are assumed to possess full information concerning the identity and collateral assets of the obligors to all contracts. Thus, distinct loan contracts will exist for each borrower.

In the second section, we define the spanning sets for consumers under four alternative bankruptcy laws, and we investigate the implications for market completeness. The role of the bankruptcy laws in creating new securities is examined by determining the conditions under which the existing spanning sets of consumers will be violated. If no consumer has the ability to alter the spanning set of another consumer and if all consumers act as though perfect substitutes sell for the same price, then the Grossman and Stiglitz [12] spanning and competitivity requirements imply that the bilateral debt market will be perfectly competitive. (See Ekern and Wilson [7], Radner [16], Grossman and Stiglitz [12], and Baron [3] on spanning sets and the requirements for perfect competition.) In such a market, arbitrage will prevent consumers from borrowing or selling short unlimited amounts at a fixed price.

In the third section, we formulate and describe the properties of a general economic equilibrium model with a perfectly competitive stock and bilateral debt market. The unique allocation of investment and consumption is derived by solving for a pseudo-default form of the equilibrium. This equilibrium is obtained by having consumers select current consumption and a security portfolio from among existing securities subject to a constraint which is equivalent, in its impact, to the imposition of a default rule. For example, a nonnegativity constraint on state-contingent consumption is equivalent, in its impact, to the imposition of an unlimited liability default rule.

\section{Properties of a Bilateral Debt Market in a General Equilibrium Setting}

\section{Economic Environment}

The economy has two periods, one nonstorable good and $S$ possible second-period states, $I$ consumers, and $J$ 
firms. The following assumptions describe the behavior of the agents in the economy and the market setting.

Firms. Each firm, indexed $j=1, \ldots, J$, possesses a unique production function, $V_{j}\left(I_{j} ; s\right)$, specifying firm output $V_{j}$ of the single commodity in state $s$ as a function of the level of investment $I_{j}$ in period 1 . When $I_{j}$ is suppressed, firm investment is assumed to be fixed. Firms issue limited liability equity claims that trade in a perfect securities market and have a total market value $P_{j}$. There exist $B$ riskless bonds offering the certain return $V_{B}=1$ with current price $P_{B}$ per bond. The market-clearing conditions are $\Sigma_{i} x_{i j}=1, j=1, \ldots, J$ and $\Sigma_{i} b_{i}=B$ where $x_{i j}$ denotes the proportion of the market value of the $j$-th firm and $b_{i}$ the number of bonds held in the $i$-th consumer's portfolio.

Consumers. There exist $I$ consumers, indexed by $i=$ $1, \ldots, I$, each possessing a concave utility function and endowments of the consumption good, $Y_{1}^{i}$ and $Y_{2}^{i}(s)$, in periods 1 and 2, respectively, and a portfolio of existing securities, $\Sigma_{j} \bar{x}_{i j} P_{j}+\bar{b}_{i} P_{B}$, where $\bar{x}_{i j}$ is the $i$-th consumer's endowed percentage holding of the $j$-th firm and $\bar{b}_{i}$ his endowed number of bonds. Consumers make decisions so as to maximize their expected utility of consumption over the two periods, $E U^{i}\left(C_{1}^{i}, C_{2}^{i}(s)\right)$, using their own subjective probabilities, for the occurrence of a given state.

Information structure. All consumers possess complete information concerning the state-contingent returns and prices of all securities. This includes complete information concerning the obligor, the promised payment, and the collateral for all contracts on which default is a possibility. All consumers know and willingly conform to the laws governing defaulted contracts.

In time-state preference general equilibrium models, each consumer maximizes $E U^{i}\left(C_{1}^{i}, C_{2}^{i}(s)\right)$ subject to a budget constraint on period 1 consumption and investment where typically $V_{j}(s)$ and $V_{B}$ are regarded as fixed constants independent of his or any other consumer's portfolio decision. This would appear to be a reasonable assumption that follows directly from the fact that $V_{j}(s)$ is defined to be the second-period market value of the total output of firm $j$ in state $s$ and $V_{B}$ is the second-period market value of the original supply $B$ of bonds guaranteed for all states by some riskless vendor like the gov- 
ernment, and no consumer is capable of influencing either of these quantities. However, in the derivation of the first-order conditions, there is nothing to prevent consumer $i$ from taking a short position in stocks (i.e., $x_{i j}<$ 0 ) or in bonds (i.e., $b_{i}<0$ ). Whenever a consumer sells a security short, he increases the total promised supply of that security by the amount of the short sale. This incremental amount of promised supply, however, is the obligation of the short seller and not of the firm or riskless vendor. Hence, even though each firm does produce $V_{j}(s)$ in state $s$ and the government pays $V_{B}$ on bonds in all states, it may still be the case that some short seller will default on his commitment.

If default by short sellers is possible and consumers know this, it is inappropriate for consumers to treat the quantities $V_{j}(s)$ and $V_{B}$ as fixed constants independent of the seller or obligor for the security. For example, with the assumptions of perfect information and the assumption that only bonds are sold short, a consumer $i$ desiring to buy $b_{i}$ bonds should recognize that he may do so either from a short seller of bonds (i.e., some consumer $k$ with $b_{k}<0$ ) or from another consumer who is selling some of his initial endowment of bonds, but who maintains a net long position (i.e., some consumer $h$ with $b_{h}-\bar{b}_{h}<0$, but $\left.b_{h}>0\right)$. If consumer $i$ buys $b_{i}$ bonds from consumer $h$, the return from this purchase will be the riskless amount $b_{i} V_{B}$. If consumer $i$ buys $b_{i}$ bonds from the short seller consumer $k$, then the return from this purchase will be the uncertain amount $b_{i} R_{k}(s)$ where

$$
R_{k}(s)=\left\{\begin{array}{lll}
V_{B} & \text { if } & A_{k}(s)+b_{k} V_{B} \geq 0 \\
\frac{-A_{k}(s)}{b_{k}} & \text { if } & A_{k}(s)+b_{k} V_{B}<0
\end{array}\right.
$$

and $A_{k}(s)$, with $\min _{s}\left(A_{k}(s)\right)=0$, represents the return in state $s$ on the collection of assets that constitute the limits of liability to the $k$-th consumer's short position. The payoffs specified in equation (1) imply that if the short seller defaults at all, he defaults on his entire short position, and each buyer is then entitled only to his pro rata share of the collateral asset return $A_{k}(s)$.

The possibility of consumer default implies that 
short sellers (borrowers) will produce a security, such as in equation (1), which is not a perfect substitute for the asset sold short. In order for consumers (both borrowers and lenders) to make portfolio decisions in this instance, they must know the structure of payoffs and prices for securities being produced by borrowers. Unlike the situation in competitive markets without consumer default in which the identity of one's trading partner is economically irrelevant, in bilateral debt markets with default it is no longer possible for traders to remain anonymous because contracts with different consumers may have different returns and prices in equilibrium.

The unique feature of any contract on which default is a possibility is that its return is contingent on the occurrence of one of two events-default versus no default. The return in the event of no default will be called the promised payment $\left(V_{B}\right.$ in equation (1)), and the return in the event of default will be called the collateral payment $\left(-A_{k}(s) / b_{k}\right)$. The default state is defined to occur whenever the collateral payment is less then the promised payment. When a consumer sells the riskless asset short, the promised payment is nonrandom. When a consumer shorts a risky asset, the promised payment will be uncertain.

The specification of the collateral payment determines the limits to the liability on debts. It will be assumed that the general class of assets that could serve as collateral will be defined by exogenously given institutional and legal provisions governing defaulted contracts. Within this general class of assets, however, borrowers and lenders will be free to negotiate a specific composition for the collateral on debts.

Default rules. Four different possible bankruptcy rules, each specifying the collection of assets serving as collateral in the event of default, are defined below for the case in which default will only occur on short positions in bonds.

1. All other assets held by a consumer (e.g., $A_{k}(s)=$ $\left.\Sigma_{j} x_{k j} V_{j}(s)+Y_{2}^{k}(s)\right)$.

2. All other assets held by a consumer with the exception of his return to human capital (e.g., $\left.A_{k}(s)=\Sigma_{j} x_{k j} V_{j}(s)\right)$. 
3. All other assets held by a consumer less a provision for some subsistence level of consumption $c_{\min }(s)$, (e.g., $\left.A_{k}(s)=\Sigma_{j} x_{k j} V_{j}(s)+Y_{2}^{k}(s)-c_{\min }(s)\right)$.

4. Only the consumer's return to human capital (e.g., $\left.A_{k}(s)=Y_{2}^{k}(s)\right)$.

Rule 1 represents unlimited liability. In this instance, default implies that the consumer's consumption in the second period is zero. Rules 2,3 , and 4 represent alternative forms of limited liability. For each of these rules, a consumer will default even though his ability to consume in the second period has not been driven to zero. In the event of default, the $i$-th consumer's consumption in the second period for rules 2,3 , and 4 will be, respectively, $c_{2}^{i}(s)=Y_{2}^{i}(s), \quad c_{2}^{i}(s)=c_{\min }(s)$, and $c_{2}^{i}(s)=$ $\Sigma_{j} x_{i j} V_{j}(s)$.

There are obviously other alternative default laws that could be defined. The most general rule would permit borrowers and lender to adopt any mutually agreed upon collection of assets as the collateral on debts. Such a default rule would be difficult to model, and it is felt that it would be more appropriate to begin the general equilibrium analysis of a bilateral debt market using the previously defined four rules, each of which has been previously used in the literature on consumer default.

It is assumed that default can only occur on a short position on at most one security, and bonds are selected as that security. This assumption allows us to isolate the effect of default itself from an exceedingly complex schedule of "me-first" or priority rules that would be needed to unambiguously specify each creditor's claim to the collateral in the event of default on more than one security.

Finally, given the assumed stock-bond market structure, default rules of some kind are clearly required to define returns in default states. However, it should be noted that for other market structures, such as one with a complete set of state-contingent contracts and perfect information, default rules would be unnecessary as consumer budget constraints would insure that default never occurs. 


\section{Consumers' Spanning Sets with a Stock and Bilateral Debt Market}

The form of the default rule affects the spanning set of consumers and degree of completeness of the stock and bilateral debt market. The concept of a spanning set, first introduced by Ekern and Wilson [7], and the concept of a complete market, first introduced by Arrow [1], have been limited in their application to markets in which consumers do not or cannot default. The meaning of these concepts in the context of a bilateral debt market can be clarified by defining the following $S$ dimensional vectors: $\underline{V_{B}}=(1, \ldots, 1)^{\prime}, V_{j}=\left(V_{j}(1), \ldots, V_{j}(S)^{\prime}\right), \underline{Y_{2}^{i}}=\left(Y_{2}^{i}(1)\right.$, $\left.\ldots, Y_{2}^{i}(S)\right)^{\prime}$, and $c_{2}^{i}=\left(c_{2}^{i}(1), \ldots, c_{2}^{i}(S)\right)^{\prime}$.

Let $C_{2}^{+}=\left[c_{2} \mid \overline{c_{2}}(s) \geq 0\right.$ for all $\left.s\right]$ be the set of all possible nonnegative, state-contingent patterns of secondperiod consumption for any consumer. The set $M_{0}^{i}=$ $\left[\underline{c_{2}^{i}} \mid \underline{c_{2}^{i}}=\Sigma_{j} x_{i j} V_{j}+b_{i} V_{B}+\underline{Y}_{2}^{i}\right.$, for all real $x_{i j}$ and $\left.b_{i}\right]$ is the spanning set, from the $i$-th consumer's perspective, for a market in which the possibility of consumer default is ignored. (If it is possible for some consumers to default on their obligations, and if consumers possess human capital which produces a possibly unique pattern of returns, then it is possible that different consumers will perceive different spanning sets for the market.) $M_{0}^{i}$ is the set of all patterns of state-contingent consumption that consumer $i$ can construct for himself by forming feasible portfolios using the securities available in the marketplace.

A market is defined to be complete, from the $i$-th consumer's perspective, whenever his spanning set contains the state-contingent consumption space $C_{2}^{+}$. It is well known that a necessary and sufficient condition for the set $M_{0}^{i}$ to represent a complete market is that $S=J+1$ and the vectors $V_{B}$ and $V_{j}, j=1, \ldots, J$, be linearly independent (see Baron [3]). Then $M_{0}^{i} \supset C_{2}^{+}$. When the number of linearly independent vectors $V_{B}$ and $V_{j}, j=1, \ldots$, $J$ is less than the number of states $\bar{S}$, then $\bar{M}_{0}^{i} \pm C_{2}^{+}$and the market is incomplete. That is, the market offers an insufficient variety of securities for the consumer to construct some patterns of state-contingent, second-period consumption in $C_{2}^{+}$. 
Define $A_{i}=\left(A_{i}(1), \ldots, A_{i}(S)\right)^{\prime}$ to be the vector of state-contingent returns on the assets, specified by the default rules, serving as collateral on the $i$-th consumer's short position in bonds.

Similarly, define $R_{i}=\left(R_{i}(1), \ldots, R_{i}(S)\right)^{\prime}$ to be the vector of state-contingent returns on the $i$-th consumer's short position in bonds where

$$
R_{i}(s)=\left\{\begin{array}{lll}
V_{B} & \text { if } \quad A_{i}(s)+b_{i} V_{B} \geq 0 \\
-\frac{A_{i}(s)}{b_{i}} & \text { if } & A_{i}(s)+b_{i} V_{B}<0 .
\end{array}\right.
$$

The set $M_{1}^{i}=\left[c_{2}^{i} \mid \underline{c_{2}^{i}}=\Sigma_{j} x_{i j} \underline{V_{j}}+b_{i} R_{i}+\underline{Y_{2}^{i}}\right.$, where $A_{i}=\Sigma_{j} x_{i j} V_{j}+Y_{2}^{i}$, for all real $x_{i j}$ and $\left.b_{i}\right]$ is the spanning

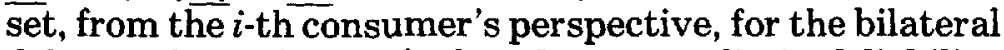
debt market when default rule 1 or unlimited liability holds. The effect is to redefine the return on bonds sold short in such a way that the consumer's consumption in the second period is $c_{2}^{i}(s)=\Sigma_{j} x_{i j} V_{j}(s)+b_{i} V_{B}+Y_{2}^{i}(s)$ in all states in which default does not occur and is zero in all states in which default does occur. This means that an equivalent definition of the spanning set is $M_{1}^{i}=\left[c_{2}^{i} \mid c_{2}^{i}=\right.$ $\Sigma_{j} x_{i j} V_{j}+b_{i} V_{B}+Y_{2}^{i}$, for all real $x_{i j}$ and $b_{i}$ such that $c_{2}^{i} \geq$ $0]$. The impact on the spanning set of the recognition of consumer default given unlimited liability is equivalent to the explicit recognition that negative consumption is infeasible. Therefore, $M_{1}^{i} \subseteq C_{2}^{+}$and the market will be complete (incomplete) when the number of securities with linearly independent vectors of state-contingent secondperiod returns is equal to (less than) the number of states.

The set $M_{2}^{i}=\left[c_{2}^{i} \mid c_{2}^{i}=\Sigma_{j} x_{i j} V_{j}+b_{i} R_{i}+\underline{Y_{2}^{i}}\right.$, where $A_{i}=\Sigma_{j} x_{i j} V_{j}$, for all real $x_{i j}$ and $\left.\bar{b}_{i}\right]$ is the spanning set, from the $i$-th consumer's perspective, for the bilateral debt market when default rule 2 holds. Default rule 2 prohibits any creditor from garnisheeing a borrower's wage income in the event of default. An equivalent definition of this spanning set is $M_{2}^{i}=\left[c_{2}^{i} \mid c_{2}^{i}=\Sigma_{j} x_{i j} V_{j}+b_{i} V_{B}+Y_{2}^{i}\right.$, for all real $x_{i j}$ and $b_{i}$ such that $c_{2}^{i} \geq Y_{2}^{i}$ ]. The impact of default rule 2 (one form of limited liability) on the spanning set is equivalent to the impact of a constraint that prohibits any consumer from forming any portfolio that 
could produce second-period consumption that is less than his wage income in some states. This means that $M_{2}^{i}$ is a proper subset of $C_{2}^{+}$, and the market will be incomplete regardless of the number of securities available in the marketplace. The market completeness characteristics of the spanning set $M_{3}^{i}$ for default rule 3 are analo gous to those for default rule 2 with the difference being that the constraint $c_{2}^{i}(s) \geq Y_{2}^{i}(s)$ for all $s$ under default rule 2 is replaced with the constraint $c_{2}^{i}(s) \geq c_{\min }(s)$ for all $s$ under default rule 3 . However, the spanning set is now identical across consumers.

The set $M_{4}^{i}=\left[c_{2}^{i} \mid c_{2}^{i}=\Sigma_{j} x_{i j} V_{j}+b_{i} R_{i}+Y_{2}^{i}\right.$, where $A_{i}=Y_{2}^{i}$, for all real $x_{i j}$ and $\left.b_{i}\right]$ is the spanning set, from the $i$-th consumer's perspective, for the bilateral debt market when default rule 4 holds. Default rule 4 restricts a creditor's claim in the event of default to the borrower's nonmarketable income. Such a situation could presumably arise if debtors could withhold from creditors any returns from their portfolio because the debtor, not the creditor, has physical possession of the claims in his investment portfolio, thereby forcing the creditor to work through a debtor's employer to place a lien on his income before the debtor receives it. Alternatively, it may be more realistic in this case to view $\mathrm{Y}_{2}^{i}$ as the return on some otherwise nonmarketable asset that is serving as the collateral on the debt.

Whenever a consumer promises a payment in some state on his short sale in bonds that exceeds his income in that state, the effect of default rule 4 is to redefine the return in that state on bonds sold short to equal the income payment in that state. This restricts a consumer's ability to use short selling of bonds to achieve certain patterns of second-period consumption. Since $M_{4}^{i}$ is a proper subset of $C_{2}^{+}$, the market is incomplete regardless of the number of distinct securities relative to the number of states.

The contents of a consumer's spanning set and its completeness depend upon (a) the trading rules of the market that define the feasible range for the values of $x_{i j}$ and $b_{i} ;$ (b) the bankruptcy rules that define the vector of returns on debts that consumers are capable of creating to alter second-period consumption; and (c) the number of linearly independent composite securities relative to the 
number of states. In summary, if the default rule is unlimited liability, rule 1 , then the market can be complete (incomplete) if the number of securities with linearly independent vectors of state-contingent second-period returns is equal to (less than) the number of states. When any limited liability default rule (rule 2-rule 4) is assumed, the stock and bilateral debt market can be incomplete regardless of the number of securities available.

\section{Perfect Competition in a Bilateral Debt Market}

Perhaps the single most important characteristic of a bilateral debt market is that when consumer default is a possibility, in most cases fairly stringent restrictions must be placed on consumer behavior in order to preserve the perfectly competitive aspects of the marketplace. The appropriate definition of perfect competition in markets with uncertainty has recently been the subject of an extensive literature dealing with the production decisions of firms. (See for example, Merton and Subrahmanyam [15], Ekern and Wilson [7], Leland [14], and Baron [3].) Grossman and Stiglitz [12] have condensed all of the various special requirements for markets to be perfectly competitive into two general requirements called spanning and competitivity. The spanning property refers to the situation in which no economic agent has the capability of altering consumption opportunities for any other consumer. The competitivity property requires that no economic agent have the capability of influencing the prices of available consumption alternatives.

The spanning property required for perfect competition to exist in the stock and bilateral debt market is Definition 1.

Definition 1-Spanning Requirement for Perfect Competition.

Define $M_{r}^{i}$ to be the spanning set, from the perspective of the $i$-th consumer, of a market in which default rule $r(r=1, \ldots, 4)$ applies. Then a market will satisfy the spanning requirement for competition if no consumer $k$ has the capability of altering the spanning set $M_{r}^{i}$ as viewed from the perspective of any other consumer $i=1, \ldots, I$. 
When an individual's debt is unique, and hence the spanning property defined in Definition 1 fails to hold, then it is possible that individuals have monopoly power.

In a bilateral debt market in which consumer default is a possibility, short sellers need to know, in addition to the fixed market prices for available securities, a pricing function or schedule that specifies a different price for each level of the short position and collateral return. However, only when the bilateral market is a perfectly competitive market will the marketplace alone provide consumers with sufficient price information to construct the pricing function that is needed.

In a perfectly competitive bilateral debt market, any return pattern that consumers can create by selling bonds short has a perfect substitute in the form of a portfolio of existing securities. In this instance, the pricing function that consumers can use is one that assigns a value to a consumer's short position in bonds that is equal to the market value of the portfolio that is the perfect substitute for the consumer's short position in bonds. Since in a perfectly competitive market, perfect substitutes must sell for the same price, the price-taking assumption that constitutes the second essential requirement for markets to be perfectly competitive is Definition 2.

\section{Definition 2-Competitivity.}

Whenever the spanning condition defined in Definition 1 holds, then a market will be perfectly competitive whenever consumers act as though perfect substitutes sell for the same price and they are incapable of influencing these prices. In particular, if it is possible to find feasible portfolio weights $\alpha_{j}, \beta_{B}$ such that $\underline{R_{k}}=\Sigma_{j} \alpha_{j} V_{j}+\beta_{B} V_{B}$, then the competitivity property will hold if consumers act as though the price they must pay to acquire the return $R_{k}$ is $L_{k}=$ $\Sigma_{j} \alpha_{j} P_{j}+\beta_{B} P_{B}$.

When it is possible for a consumer by selling bonds short to create a pattern of state-contingent returns for which a perfect substitute does not exist (i.e., when de- 
fault rule 4 is assumed without additional trading rule restrictions or under any default rule when $J+1<S$ ), then the market does not provide sufficient information for consumers to construct a pricing function.

\section{A General Equilibrium Model with Consumer Default}

\section{The Model}

The market setting continues to be that described by assumptions 1-4 with the following additional assumption:

5. Perfect Competition. The Grossman and Stiglitz [12] spanning (Definition 1) and competitivity (Definition 2) requirements for perfect competition are both satisfied.

Initially, default rule 4 will be invoked. That is, liability is limited to a consumer's nonmarketable return to human capital. It is assumed that default is only possible on short positions in bonds.

Assumption 4 implies that debt contracts will be onedimensional and is invoked at this point to make the analysis as simple as possible. Notice that given assumption 4 , in order for assumption 5 to hold, all consumers' return to human capital must be perfect substitutes for one another, and the trading rules in the market must restrict consumers to only create risky debt that can be duplicated by existing stock market assets.

In a bilateral debt market, it is necessary to identify the obligor or the seller of contracts on which default is possible. In a bilateral debt market, it is also necessary that borrowers and lenders have equivalent control over each of the dimensions determining the returns on contracts on which default is possible. To accommodate these requirements, the following notation will be used:

$b_{i}=$ the number of bonds on which default cannot occur held by consumer $i$. Therefore, $b_{i}$ controls the amount of riskless borrowing or lending engaged in by consumer $i$.

$d_{i k}=$ the number of bonds on which default can occur that consumer $i$ (acting as a lender) prefers that consumer $k$ lacting as a borrower) sell short in total. Therefore, $d_{i k}$ con- 
trols the size of the total promised payment that consumer $i$ prefers be offered on the debt of consumer $k$.

$z_{i k}=$ the number of bonds on which default can occur purchased by consumer $i$ from the short seller consumer $k$. Therefore, $z_{i k}$ controls the amount loaned to consumer $k$ by consumer $i$ as a percentage of the total amount loaned to consumer $k$.

$R_{i k}(s)=$ the return in state $s$ per bond that is sold short by consumer $k$ and on which default can occur when the short position is structured according to the preferences of consumer $i$. For example, given assumption 4 ,

$$
R_{i k}(s)=\left\{\begin{array}{lll}
V_{B} & \text { if } \quad Y_{2}^{k}(s) \geq d_{i k} V_{B} \\
\frac{Y_{2}^{k}(s)}{d_{i k}} & \text { if } \quad Y_{2}^{k}(s)<d_{i k} V_{B}
\end{array}\right.
$$

In other words, $R_{i k}(s)$ is the return in state $s$ per unit of risky debt created by consumer $k$ when the terms of that debt contract are set according to the preferences of consumer $i$.

$L_{i k}=$ the market value per bond sold short by consumer $k$ and on which default can occur when the return in state $s$ per bond sold short is given by $R_{i k}(s)$. In other words, $L_{i k}$ is the market value per unit of risky debt created by consumer $k$ when the terms of that debt are set according to the preferences of consumer $i$.

To include the possibility that consumers enter the first period endowed with previously held short positions or debts, the variables $\bar{b}_{i}, \bar{d}_{i k}$, and $\bar{z}_{i k}$ will be introduced to represent the initial endowment levels for the abovedefined variables.

Given this new notation, plus that previously defined, and the assumptions, the $i$-th consumer's secondperiod consumption in state $s$ is given by

$$
\begin{aligned}
c_{2}^{i}(s)=\sum_{j} x_{i j} V_{j}(s)+ & Y_{2}^{i}(s)+b_{i} V_{B} \\
& -d_{i i} R_{i i}(s)+\sum_{k=1}^{I} z_{i k} R_{i k}(s) .
\end{aligned}
$$


In equation (2), the term $d_{i i} R_{i i}(s)$ represents the returns that consumer $i$ prefers to pay on any short position he takes in bonds on which he defaults in some states of nature. Finally, the term $\Sigma_{k=1}^{I} z_{i k} R_{i k}(s)$ represents the returns consumer $i$ receives by buying the debts of other consumers. Notice that the term in the summation for which $k=i$ is $z_{i i} R_{i i}(s)$, which represents the number of bonds sold short by consumer $i$ that are bought back by consumer $i$. It is important to note that with the variable $d_{i i}$, consumer $i$ can alter the total promised payment on the short position or debt that he issues. With $d_{i i}$ fixed, the returns on this debt contract are fixed, and with the variable $z_{i i}$, consumer $i$ can, like any other consumer, trade in the debt security he has just created without altering the defined returns on that security. It must be remembered that a short sale on which default is possible offers returns distinct from those on a short sale for which default is not possible, and therefore, the short sale on which default is possible will trade in the marketplace as a separate security. The process of a consumer buying a portion of the debt he issues has a more familiar interpretation in the context of a model that represents default as occurring on personal debts made directly between consumers or on loans made through a financial intermediary. For example, a consumer may take out a loan from a financial intermediary and effectively buy back a portion of that loan by buying stock in the financial intermediary. Note that constraint (7) implies that $d_{i i}$ must be positive if $\min _{s}\left(Y_{2}^{i}(s)\right)>0$. However, if consumer $i$ does not wish to issue any risky debt, then he will select $z_{i i}=d_{i i}$.

The $i$-th consumer's initial wealth, ignoring the settlement aspects of default in the first period, is given by

$$
W_{i}=Y_{1}^{i}+\sum_{j} \bar{x}_{i j} P_{j}+\bar{b}_{i} P_{B}-\bar{d}_{i i} L_{i i}+\sum_{k=1}^{I} \bar{z}_{i k} L_{i k} \text {. }
$$

The consumption-investment problem facing consumer $i$ is

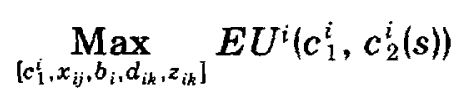

subject to

$$
\sum_{j} x_{i j} P_{j}+b_{i} P_{B}-d_{i i} L_{i i}+\sum_{k} z_{i k} L_{i k}+c_{1}^{i}=W_{i}
$$




$$
\begin{aligned}
& b_{i} \geq-\frac{Y_{2}^{i}(s)}{V_{B}} s=1, \ldots, S \\
& d_{i k} \geq \frac{\min _{s}\left(Y_{2}^{k}(s)\right)}{V_{B}} \quad k=1, \ldots, I \\
& b_{i}\left(d_{i i}-z_{i i}\right) \geq 0 .
\end{aligned}
$$

Constraint (5) is the $i$-th consumer's budget constraint. The range of short positions in bonds is defined by constraints (6) to (8). Constraint (6) identifies the range in which default cannot occur, (7) defines the range in which default occurs in at least one state (risky debt), and (8) insures that only one class of debt can be issued. Let $\lambda_{i}, \gamma_{i s}, s=1, \ldots, S, \delta_{i k}, k=1, \ldots, I$, and $\xi_{i}$ denote the multipliers associated with the constraints (5), (6), (7), and (8), respectively.

It should be noted that two of the requirements for the Kuhn-Tucker conditions to provide both necessary and sufficient conditions for an optimal solution to the problem are not strictly satisfied: differentiability and convexity. Equations (4) and (5) have points at which derivatives with respect to $d_{i k}$ do not exist. Those points correspond to the situation where the number of states in which an individual defaults changes. At all other points, the functions are differentiable. We are assuming that the optimum is occurring at one of these points rather than including the cumbersome constraints to eliminate these points that would add little economic insight.

Constraints (5) and (8) are bilinear forms, which have the characteristic of nonconvexity. To see the source of the nonconvexity in (5), consider the case in which it is possible to define state-contingent prices $q_{\mathrm{s}}, s=1, \ldots$, $S$. Then

$$
\sum_{k} z_{i k} L_{i k}=\sum_{k}\left[z_{i k} \sum_{s \in S^{*}} q_{s} V_{B}+z_{i k} \sum_{s \in S^{\prime}} q_{s} \frac{Y_{2}^{k}(s)}{d_{i k}}\right]
$$

where

$$
S^{*}=\left(s \mid y_{2}^{k}(s) \geq d_{i k} V_{B}\right) \text {, and } S^{\prime}=\left(s \mid Y_{2}^{k}(s)<d_{i k} V_{B}\right) .
$$

The last term inside the bracket of the equation causes the function to be nonconvex in $z_{i k}$ and $d_{i k}$. See Dreze [6] for a proof in another context and an example in Hart [13]. This nonconvexity will mean that the Kuhn-Tucker 
conditions provide necessary but not always sufficient conditions for an optimal solution.

The market-clearing conditions for the bilateral debt market given perfect competition are

$$
\begin{aligned}
& \sum_{i} x_{i j}=1 \quad j=1, \ldots, J \\
& \sum_{i} b_{i}=B \\
& d_{i i}=d_{k i} \quad \begin{array}{l}
\text { for all } k \neq i \\
i=1, \ldots, I
\end{array} \\
& \sum_{i} z_{i k}=d_{k k} \quad k=1, \ldots, I .
\end{aligned}
$$

Condition (9) clears the market for equity shares in firms. Condition (10) clears the market for riskless debt, and condition (12) clears the market for risky debt. Condition (11) requires that all borrowers and lenders agree on the terms of all risky debt contracts. Due to assumption 4, debt contracts are one-dimensional and, therefore, condition (11) involves the single class of decision variables $d_{i k}$.

\section{Equivalent Representation of a Perfectly Competitive Equilibrium with Consumer Default}

In equilibrium, each consumer will have created for himself a particular state-contingent vector of secondperiod consumption that lies in his spanning set. However, when perfect substitutes exist in the market, it is possible for the consumer to use different portfolios to generate the same consumption vector. It follows that there will exist multiple, equivalent representations of a perfectly competitive equilibrium with consumer default that differ only in terms of consumers' relative investment in a group of assets that are perfect substitutes. For example, in the previous section, an equilibrium was set forth in which consumers create specific debt obligations with returns $R_{i k}(s)$ for $k=1, \ldots, I$. This representation will be called the default form for general equilibrium because it represents consumers creating securities for which default occurs in some states. However, another equivalent representation of equilibrium is one in which consumers are instead depicted as holding a short position in the portfolio of existing assets that is a per- 
fect substitute for the debt obligations issued in the default form equilibrium. By definition, that consumer can successfully honor the contracted payments in each state on his short position in that portfolio, and therefore it appears as though no default is occurring. This representation will be called the pseudo-default form for the general equilibrium.

The notion and relevance of equivalent representations for the general equilibrium can be made more rigorous by demonstrating the following:

1. In equilibrium a consumer is indifferent at the margin concerning his relative investment in assets that are perfect substitutes.

2. Given a specific equilibrium in the default form, it is easy to express the equilibrium in the pseudodefault form. Given a specific equilibrium in the pseudo-default form, however, there may exist an infinite number of default forms for the equilibrium. In this instance, it is impossible to solve for a unique structure to the bilateral debt market.

3. It is possible to identify a set of constraints which, when applied to a model that is not adjusted for default, will produce an equilibrium equivalent to any default form equilibrium.

Consumer indifference between perfect substitutes. In order to distinguish so-called "existing" securities from securities that consumers are about to create, an existing security is defined as one whose vector of returns is considered as fixed, whereas a security about to be created is one whose return vector is part of the current decision set of consumers. With investment in firms fixed, the set of existing securities will include the equity securities of firms and riskless bonds. To focus on the new debt issue, it is assumed that there are no preexisting debt contracts, $\left(\bar{d}_{i k}=\bar{z}_{i k}=0\right.$ for all $i$ and $\left.k\right)$.

Given this definition for the set of existing securities, it follows that the spanning and competitivity requirements for perfect competition imply that it must be possible to find a set of weights $\alpha_{i j k}$ and $\beta_{i k}(i, k=1, \ldots, I$ and $j=1, \ldots, J)$ such that

$$
R_{i k}(s)=\sum_{j} \alpha_{i j k} V_{j}(s)+\beta_{i k} V_{B} \quad \text { for all } i, k, s
$$


and

$$
L_{i k}=\sum_{j} \alpha_{i j k} P_{j}+\beta_{i k} P_{B} \quad \text { for all } i, k .
$$

The weights are actually functions of the terms of the debt contracts. Given assumption 4 , only the variables $d_{i k}$ control these terms, and therefore the weights should be written as implicit functions of $d_{i k}$ such as $\alpha_{i j k}\left(d_{i k}\right)$ and $\beta_{i k}\left(d_{i k}\right)$. To simplify the notation, the implicit function notation is suppressed.

Expressions (13) and (14) can be substituted into the Kuhn-Tucker conditions for the default form of the model. For example, since the Kuhn-Tucker necessary marginality conditions for the decision variables $d_{i k}(k=$ $1, \ldots, I$ ), consumer $i$ 's control of the promised payment of the $k$-th consumer's short position, is exactly equal to zero regardless of the value of $d_{i k}$, then consumer $i$ is indifferent to the value of $d_{i k}$. It will now be shown that if consumer $i$ has already selected his optimal portfolio of existing securities, given by $x_{i j}$ and $b_{i}$, then in perfectly competitive markets it appears that he is indifferent to the value of $d_{i k}$.

Assume that it is optimal for consumer $k$ to sell bonds short past the point in which he defaults in some state, implying that constraint (7) will be nonbinding and hence its multiplier is zero. Expressions (13) and (14) can be substituted into the Kuhn-Tucker condition and rearranged to give

$$
\begin{aligned}
z_{i k}\left[\sum_{j} \alpha_{i j k}^{\prime}\left(E \frac{\partial U^{i}}{\partial c_{2}^{i}(s)} V_{j}(s)-\lambda_{i} P_{j}\right)\right] \\
+z_{i k}\left[\beta_{i k}^{\prime}\left(E \frac{\partial U^{i}}{\partial c_{2}^{i}(s)} V_{B}-\lambda_{i} P_{B}\right)\right]=0 \\
\text { for } k \neq i .
\end{aligned}
$$

At equilibrium, the Kuhn-Tucker conditions for investment in firms and riskless debt will hold, and when these conditions are substituted into (15) one obtains

$$
z_{i k}\left(\sum_{s} \gamma_{i s}+\xi_{i}\left(d_{i i}-z_{i i}\right)\right)=0
$$

where $\gamma_{i s}$ and $\xi_{i}$ are multipliers associated with constraints (6) and (8), respectively. 
Equation (16) implies that whenever consumer $i$ holds riskless bonds $\left(\gamma_{i s}=0\right.$ for all $\left.s\right)$ and simultaneously issues risky debt $\left(\xi_{i}=0\right)$, then since the marginality conditions for $x_{i j}$ and $b_{i}$ hold, it follows that the marginality conditions for the debt terms $d_{i k}$ will also hold. Therefore, consumer $i$ is indifferent to the debt terms $d_{i k}$. If consumer $i$ holds riskless bonds $\left(\gamma_{i s}=0\right.$ for all $\left.s\right)$ and $\xi_{i} \neq 0$, then $d_{i i}=z_{i i}$ and indifference to the debt terms $d_{i k}$ follows. On the other hand, if consumer $i$ issues enough riskless bonds so that $\gamma_{i s} \neq 0$ for some $s$ and no risky debt is issued $\left(d_{i i}-z_{i i}=0\right)$, then in equilibrium it must be that $z_{i k}=0$, in which case consumer $i$ is again indifferent to the debt terms $d_{i k}$.

The pseudo-default form for the equilibrium. Assume that $P_{1}^{*}, \ldots, P_{j}^{*}, P_{B}^{*}$, and $L_{1}^{*}, \ldots, L_{I}^{*}$, constitute a set of equilibrium prices for the default form of the model and assume that $c_{1}^{i *}, x_{i j}^{*}, j=1, \ldots, J, b_{i}^{*}$, and $d_{i k}^{*}, k=1, \ldots$, $I$ represent a set of equilibrium consumption and investment decisions for consumer $i$ for the default form of the model. This implies that the $i$-th consumer's secondperiod consumption in state $s$ will be

$$
\begin{aligned}
c_{2}^{i *}(s)=\sum_{j} x_{i j}^{*} V_{j}(s)+b_{i}^{*} V_{B}-d_{i i}^{*} R_{i i}(s) & \\
& +\sum_{k} z_{i k}^{*} R_{i k}(s)+Y_{2}(s) .
\end{aligned}
$$

The spanning requirement for perfect competition requires that there exists a set of weights $\alpha_{i j k}^{*}$ and $\beta_{i k}^{*}$ such that

$$
R_{i k}(s)=\sum_{j} \alpha_{i j k}^{*} V_{j}(s)+\beta_{i k}^{*} V_{B} .
$$

Substituting (18) into (17) and after collecting common terms, we can write $c_{2}^{i *}(s)$ as

$$
\begin{aligned}
c_{2}^{i *}(s)=\sum_{j}\left(x_{i j}^{*}\right. & \left.-d_{i i}^{*} \alpha_{i j i}^{*}+\sum_{k} z_{i k}^{*} \alpha_{i j k}^{*}\right) V_{j}(s) \\
& +\left(b_{i}^{*}-d_{i i}^{*} \beta_{i i}^{*}+\sum_{k} z_{i k}^{*} \beta_{i k}^{*}\right) V_{B}+Y_{2}^{i}(s) .
\end{aligned}
$$

Defining

$$
\hat{x}_{i j}=x_{i j}^{*}-d_{i i}^{*} \alpha_{i j i}^{*}+\sum_{k} z_{i k}^{*} \alpha_{i j k}^{*}
$$


and

$$
\hat{b}_{i}=b_{i}^{*}-d_{i i}^{*} \beta_{i i}^{*}+\sum_{k} z_{i k}^{*} \beta_{i k}^{*},
$$

we can write the $i$-th consumer's second-period consumption in state $s$ as

$$
c_{2}^{i *}(s)=\sum_{j} \hat{x}_{i j} V_{j}(s)+\hat{b}_{i} V_{B}+Y_{2}^{i}(s) .
$$

Therefore, consumer $i$ can produce the identical statecontingent pattern of consumption in the second period that he obtained in the default form of equilibrium by holding the portfolio $\hat{x}_{i j}, j=1, \ldots, J$, and $\hat{b}_{i}$ on which the consumer does not default on any security.

Therefore, if $P_{j}^{*}, P_{B}^{*}, L_{i}^{*}, c_{1}^{i *}, x_{i j}^{*}, b_{i}^{*}$, and $d_{i k}^{*}$ constitute an equilibrium in default form, then the equivalent equilibrium in the pseudo-default form is given by $P_{j}^{*}$, $P_{B}^{*}, c_{1}^{i *}, \hat{x}_{i j}$, and $\hat{b}_{i}$. The two equilibria are equivalent because they produce the same aggregate level of investment for each asset and the same level of state-contingent consumption for all consumers.

Associated with any given default form of equilibrium, there will be a unique pseudo-default form of equilibrium (assuming $J+1 \leq S$ ). However, the converse of this statement is not always true. For example, there will not exist a unique default form equilibrium whenever a given equilibrium pattern of state-contingent consumption (given in (17)) can be duplicated using different values for the portfolio demands $x_{i j}, b_{i}$, and $d_{i k}$ all of which continue to satisfy the market-clearing conditions. To see how such a situation might develop, assume that only consumer $i$ holds a short position in bonds on which default occurs for some states and that liability is unlimited (default rule 1). Then, in equilibrium, in those states in which default does not occur, the $i$-th consumer's secondperiod consumption will be

$$
c_{2}^{i}(s)=\sum_{j} x_{i j} V_{j}(s)-d_{i i} V_{B}+Y_{2}^{i}(s),
$$

and in those states in which default does occur, consumption will be zero. Within the range of the decision variables $x_{i j}, b_{i}$, and $d_{i i}$ in which the default status of each state does not change, any set of portfolio demands that satisfies (22) for the set of states in which default does 
not occur will be equivalent to the equilibrium demands. However, whenever the number of states in which default does not occur is less than $J+1$, then it is impossible to rule out the possibility that multiple sets of portfolio demands satisfy (22).

Similarly, on the lending side, the second-period consumption for any consumer $k \neq i$ in states in which default by consumer $i$ does not occur will be

$$
c_{2}^{k}(s)=\sum_{j} x_{k j} V_{j}(s)+b_{k} V_{B}+z_{k i} V_{B}+Y_{2}^{k}(s),
$$

and in states in which default does occur will be

$$
\begin{aligned}
c_{2}^{k}(s)=\sum_{j} x_{k j} V_{j}(s)+b_{k} V_{B}+\frac{z_{k i}}{d_{i i}}\left(\sum_{j} x_{i j} V_{j}(s)\right. & \\
& \left.+Y_{2}^{i}(s)\right)+Y_{2}^{k}(s) .
\end{aligned}
$$

For a given set of portfolio demands for consumer $i$, there may be multiple sets of equivalent portfolio demands $x_{k j}$, $b_{k}$, and $z_{k i}$ for consumer $k$ whenever $J+2>S$.

The implications of this indeterminateness is that when competitive market assumptions hold, it may be impossible to determine the allocation of risky debt across consumers. This indeterminateness is analogous to the situation, also in perfectly competitive markets, in which it is impossible to determine the allocation of investment across the firms within an industry. In each case, the indeterminateness results from the fact that consumers are indifferent to the relative level of investment in assets that are perfect substitutes.

Constraints for the pseudo-default form of the model. In the previous subsection, it was shown that given an equilibrium in the default form, it is a simple matter to specify the equilibrium in the pseudo-default form. However, this does not imply that one can derive the pseudodefault form of equilibrium that is equivalent to the default form by simply solving an unconstrained optimization in which default possibilities are ignored. However, it is possible to specify a set of constraints that will produce a solution in pseudo-default form that is equivalent to any default form solution. In other words, in a perfectly competitive economy, there exists a set of constraints whose impact on prices, investment, and 
portfolio demands is equivalent to the impact of the explicit recognition of the possibility of consumer default.

In order to identify the form of these constraints, it is necessary to refer back to equations (19) and (20), which related demands in the pseudo-default form (indicated with $\mathrm{a}^{\wedge}$ ) to demands in the default form (indicated with an *). The only constraint restricting the feasible values of the variables to the right of the equal sign in (19) and $(20)$ is the spanning requirement for perfect competition, which requires that the value of the weights $\alpha_{i j k}$ and $\beta_{i k}$ be such that the returns on any debt securities consumers create lie within the spanning set. It follows that the constraint that must be applied to the demands $x_{i j}$ and $b_{i}$ is that they produce only portfolios whose returns fall within the appropriate spanning set for this market. It was shown that the spanning set for a bilateral debt market under default rule 4 is

$$
\begin{aligned}
M_{4}^{i}= & {\left[c_{2}^{i} \mid c_{2}^{i}(s)=\sum_{j} x_{i j} \underline{V_{j}}+b_{i} \underline{V_{B}}-d_{i i} \underline{R_{i i}}\right.} \\
& +\sum_{k} z_{i k} \underline{R_{i k}}+\underline{Y_{2}^{i}} \text { for all } x_{i j}, z_{i k} \text { and } b_{i}
\end{aligned}
$$

and $d_{i i}$ subject to (6), (7)].

Therefore, the constraint that must be placed on the selection of $\hat{x}_{i j}$ and $\hat{b}_{i}$ is that they fall in the set $\Gamma_{4}$ where

$$
\Gamma_{4}=\left[\left(\hat{x}_{i j}, \hat{b}_{i}\right) \mid \sum_{j} \hat{x}_{i j} \underline{V_{j}}+\hat{b}_{i} \underline{V_{B}}+\underline{Y_{2}^{i}} \in M_{4}^{i}\right] \text {. }
$$

This implies that the solution to the following constrained optimization will produce a pseudo-default form equilibrium with the same prices, investment, and statecontingent levels of consumption as any default form equilibrium produced by the stock and bilateral debt market model in (4)-(8):

$$
\max _{\left[x_{i j}, b_{i}, c_{1}^{i}\right]} E U^{i}\left(c_{1}^{i}, \sum_{j} x_{i j} V_{j}(s)+b_{i} V_{B}+Y_{2}^{i}(s)\right)
$$

subject to

$$
\begin{aligned}
& W_{i}=\sum_{j} x_{i j} P_{j}+b_{i} P_{B}+c_{1}^{i} \\
& \left(x_{i j}, b_{i}\right) \in \Gamma_{4} .
\end{aligned}
$$

Constraint (25) can be written in a more explicit form 
when default rule 1, 2, or 3 holds. For example, it can be recalled that the spanning set for the bilateral debt market when default rule 1 , or unlimited liability, holds can be written as

$$
M_{1}^{i}=\left[\underline{c_{2}^{i}} \mid \underline{c_{2}^{i}}=\sum_{j} x_{i j} \underline{V_{j}}+b_{i} \underline{V_{B}}+\underline{Y_{2}^{i}},\right.
$$

for all $x_{i j}$ and $b_{i}$ such that $c_{2}^{i} \geq 0$ ].

It is clear, therefore, that when default rule 1 holds, the substitution for constraint (25) will take the explicit form

$$
c_{2}^{i}(s)=\sum_{j} x_{i j} V_{j}(s)+b_{i} V_{B}+Y_{2}^{i}(s) \geq 0
$$

for all $s$.

This means that when markets are perfectly competitive and liability is unlimited, the impact of the potential for consumer default on equilibrium is equivalent to the impact of nonnegativity constraints on state-contingent consumption.

Finally, the forms of the constraint for the case of default rules 2 and 3, respectively, are

$$
c_{2}^{i}(s) \geq Y_{2}^{i}(s) \text { for all } s
$$

and

$$
c_{2}^{i}(s) \geq c_{\min }(s) \text { for all } s .
$$

It is somewhat ironical that in perfectly competitive markets the impact of the possibility for consumer default, in the case of default rules 1-3, should be equivalent to the imposition of constraints such as (26)-(28), which rule out the possibility of default occurring on a portfolio of existing securities. Of course, the reason for this result is that whenever these constraints are violated, the role of the spanning requirement of perfectly competitive markets is to redefine the returns on securities in such a way that these constraints are satisfied.

\section{References}

[1] Arrow, K. "The Role of Securities in the Optimal Allocation of Risk-Bearing." Review of Economic Studies 31(April 1964):9196. 
[2] Arrow, K., and F. Hahn. General Competitive Analysis. Oakland, CA: Holden-Day, 1971.

[3] Baron, D. "On the Relationship between Complete and Incomplete Financial Market Models." International Economic Review 20(February 1979):105-117.

[4] Debreu, G. Theory of Value. New York: Wiley, 1959.

[5] Diamond, P. "The Role of a Stock Market in a General Equilibrium Model with Technological Uncertainty." American Economic Review 57(September 1967):759-776.

[6] Dreze, J. H. "Investment under Private Ownership: Optimality Equilibrium and Stability." In Allocation under Uncertainty: Equilibrium and Optimality, edited by J. Dreze. Paris: International Economic Association, 1974.

[7] Ekern, S., and R. Wilson. "On the Theory of the Firm in an Economy with Incomplete Markets." Bell Journal of Economics and Management Science 5(Spring 1974):171-180.

[8] Gevers, L. "Competitive Equilibrium of the Stock Exchange and Pareto Efficiency." In Allocation under Uncertainty: Equilibrium and Optimality, edited by J. Dreze. Paris: International Economic Association, 1974.

[9] Grandmont, J. "On the Temporary Competitive Equilibrium." Working Paper No. 305, Center for Research in Management Sciences, University of California, Berkeley, August, 1970.

[10] Green, J. "Pre-existing Contracts and Temporary General Equilibrium." In Essays in Economic Behavior under Uncertainty, edited by M. S. Balch, D. L. McFadden, and S. Y. Wu. Amsterdam: North-Holland, 1974, pp. 263-286.

[11] Grossman, S., and O. Hart. "A Theory of Competitive Equilibrium in Stock Market Economies." Econometrica 47(March 1979):293-330.

[12] Grossman, S., and J. Stiglitz. "Stockholder Unanimity in Making Production and Financial Decisions." Quarterly Journal of Economics 94(May 1980):543-566.

[13] Hart, O. "Take-Over Bids and Stock Market Equilibrium." Journal of Economic Theory 16(February 1977):53-83.

[14] Leland, H. "Production Theory and the Stock Market." Bell Journal of Economics and Management Science 5(Spring 1974):125-144.

[15] Merton, R. C., and M. Subrahmanyam. "The Optimality of a Competitive Stock Market." Bell Journal of Economics and Management Science 5(Spring 1974):125-144.

[16] Radner, R. "A Note on the Unanimity of Stockholders' Preferences among Alternative Production Plans: A Reformulation of the Ekern-Wilson Model." Bell Journal of Economics and Management Science 5(Spring 1974):181-184. 
[17] Stigum, B. "Competitive Equilibria under Uncertainty." Quarterly Journal of Economics 83(November 1969):533-561.

[18] Stigum, B. "Resource Allocation under Uncertainty." International Economic Review 13(October 1972):431-459. 